\title{
Adherence to Oral Nutritional Supplements After Being Discharged from the Hospital is Low but Improves Outcome in Patients with Advanced Chronic Liver Disease
}

This article was published in the following Dove Press journal:

Patient Preference and Adherence

\section{Lubomir Skladany (D) \\ Jana Vnencakova (D) \\ Lukas Laffers ${ }^{2}$ \\ Beata Skvarkoval \\ Eva Hrubál \\ Pavol Molcan' \\ Tomas Koller iD ${ }^{3}$ \\ 'Hepatology, Gastroenterology and Transplantation (HEGITO) Department of the 2nd Department of Medicine, Slovak Medical University, FD Roosevelt Hospital, Banska Bystrica, Slovakia; ${ }^{2}$ Department of Mathematics, Faculty of Natural Sciences, Matej Bel University, Banska Bystrica, Slovakia; ${ }^{3}$ Gastroenterology and Hepatology Subdiv. of the 5th Department of Medicine, Comenius University Faculty of Medicine, University Hospital Bratislava, Bratislava, Slovakia}

Correspondence: Tomas Koller Gastroenterology and Hepatology Subdiv. of the 5th Department of Medicine,

Comenius University Faculty of Medicine, University Hospital Bratislava, Ruzinovska

6. Bratislava 82606, Slovakia

Tel +421905I8692

Email koller.tomas@gmail.com
Purpose: Patients with advanced chronic liver disease (ACLD) often have a poor nutritional status. In the management, current guidelines recommend dietary counseling and oral nutritional supplements (ONS). Nutritional goals and adherence to ONS are difficult to achieve while studies addressing adherence are scarce. We aimed to evaluate adherence to ONS, the associated factors, and its impact on outcome among ALCD patients who are discharged from the hospital.

Patients and Methods: We identified consecutive hospitalized patients with ACLD from the cirrhosis registry and ONS prescription at discharge. Baseline demographics, anthropometrics, hand-grip strength (HGS), nutritional, and laboratory parameters were recorded. Adherence was assessed at 30, 90, and 180 days, but not in patients who did not survive or in those who underwent liver transplantation (LT) before the time-point.

Results: From the registry containing 1004 patients, we included 450 cases, the median age was 56.3 (IQR 47-62), 60\% were males, 63.8\% had alcoholic etiology, and the median model for end-stage liver disease score (MELD) was 16 (11-21). During follow-up, 13.6\%, 23.6\%, and $31.1 \%$ of patients have died within 30, 90, and 180 days, respectively, and 21 underwent LT. Adherence to ONS in surviving patients was observed in 46\%, 26.1\%, and $16.9 \%$ within 30,90 , and 180 days, respectively. Baseline refractory ascites $(\mathrm{HR}=0.43,0.24-0.76), \mathrm{HGS}(\mathrm{HR}=1.03$, 1.01-1.06), and mid-arm circumference ( $\mathrm{HR}=0.93,0.88-0.99)$ were independently associated with 30-day adherence. Among patients who survived beyond 30 days, adherents for $>30$ days had improved synthetic liver function, HGS, a higher probability of LT $(\mathrm{HR}=1.7,1.03-2.8)$ and lower risk of death $(\mathrm{HR}=0.65,0.45-0.89)$, particularly those with $\mathrm{MELD}>16(\mathrm{OR}=0.55,0.36-$ $0.85)$ and low HGS (OR=0.61, 0.39-0.93).

Conclusion: In ACLD patients after discharge, adherence to ONS steeply declined and was associated with baseline refractory ascites and low muscle strength. Adherence to ONS also improved liver function, muscle strength, and survival.

Keywords: adherence, nutritional supplements, malnutrition, cirrhosis, outcome, prognosis

\section{Introduction}

Advanced chronic liver disease (ACLD) is a frequent cause of premature death in Central European countries. ${ }^{1}$ Among hospitalized ACLD patients, impaired nutritional status has been reported in $46 \%$ to $95 \%$ of cases. ${ }^{2,3}$ Presumed mechanisms for the condition are decreased energy intake and absorption of nutrients, ${ }^{4}$ increased energy expenditure, and impaired gluconeogenesis with altered starvation 
metabolism. ${ }^{5}$ There is evidence that malnourished or sarcopenic patients are at risk of cirrhosis decompensation, ${ }^{6}$ poor outcomes of liver transplantation (LT), and death. ${ }^{7}$ In the management of the conditions, two recent international practice guidelines recommend dietary counseling combined with oral nutritional supplements (ONS) when necessary. ${ }^{89}$ Currently, there is conflicting evidence of the beneficial effect of enteral nutrition in hospitalized patients with severe disease. ${ }^{10,11}$ Also, it has been reported that protein and energy supplementation are difficult to achieve. ${ }^{12,13} \mathrm{~A}$ recent meta-analysis has concluded that reduction of the post-absorptive phase could reverse anabolic resistance and sarcopenia. ${ }^{14}$ ONS thus represent a convenient solution in improving energy intake after discharge providing easily available nutrients in a sufficient amount. ${ }^{15,16}$

Adherence is defined by the World Health Organization as the extent to which a person's behavior such as taking medication, following a diet, or executing a certain lifestyle corresponds with agreed recommendations from a health care provider. ${ }^{17,18}$ There is currently no consensus on a quantitative definition of adherence, but it generally requires uptake of more than $80 \%$ of a recommended medication. ${ }^{19,20}$ Adherence to medications for chronic diseases has been previously reported in the range of $43-78 \%{ }^{21,22}$ and likewise in patients with cirrhosis. ${ }^{23,24}$ However, studies on adherence to ONS and reports on its impact on the outcome have not been adequately powered or lacked disease severity stratification. ${ }^{25}$ Hence, we aimed to evaluate the rate of adherence to ONS among discharged ACLD patients, to explore factors associated with adherence as well as its impact on ALCD outcome and prognosis.

\section{Materials and Methods}

HEGITO7 registry contains data on consecutive hospitalized patients at the Hepatology, gastroenterology, and transplantation unit (HEGITO) with the established diagnosis of advanced chronic liver disease (ACLD) since $2014 .^{26}$ The registry was initiated in our unit at the Department of Hepatology, Gastroenterology and Transplantation in 2014 and we are unique creators and owners of the registry data. The unit also provides an LT program for the entire country. The inclusion criteria for the registry are hospitalization for ACLD, informed consent, and either one of the following: a decompensating event of cirrhosis requiring hospitalization such as variceal bleed, ascites, infection, alcoholic hepatitis or hepatic encephalopathy (HE), pre-LT evaluation of potential candidates, and hospitalization for hepatocellular carcinoma (HCC) within the Milan criteria requiring intervention with curative intent. We excluded patients who were hospitalized for other elective procedures, patients with terminal stages of ACLD or HCC as well as patients with very limited life expectancy due to comorbid conditions. The registry contains the date of index hospitalization, basic demographics, medical history, etiology of cirrhosis, cirrhosis complications (ie refractory ascites, RA), and body mass index. Also, it includes handgrip strength (HGS, in $\mathrm{kg}$ ) measured with the dynamometer Kern MAP80, a mid-arm circumference (MAC, in $\mathrm{cm}$ ), and a tricipital skinfold (in mm) using a standard Harpenden type caliper Somet. During hospitalization, we also recorded laboratory parameters (blood count, inflammatory markers, markers of synthetic liver function), MELD-Na score (further referred to as MELD), Child-Pugh-Turcotte score, the time needed to complete the number connection test $(25$ numbers).

For this study, we have identified patients in the registry with ONS prescriptions at discharge from the hospital. The indication for ONS prescription has been the formal diagnosis of malnutrition made by a trained hepatologist, or according to the recent ESPEN Guidelines, to overcome issues associated with the provision of calories and nutrients. ${ }^{9}$ The diagnosis of malnutrition has been based on any combination of the following: eyeball test, anthropometric measurements, HGS, laboratory data, and psoas muscle measurement (on computed tomography $[\mathrm{CT}]$ ).

Before discharge, trained nurses (JV, BS) provided to patients at least 30-minute nutritional counseling with detailed instructions on the adequate doses and sources of proteins (eg content of proteins per palm-of-a-hand meat serving, egg, milk, tofu, ONS, etc.), on the importance of the maximum time interval between meals ( 4 hours), and the late-evening snack. ${ }^{27,28}$ Written and graphic instructions were also provided to patients for further reference. ONS have been recommended in the form of "sipping" to complement the source of energy and protein provided by regular meals and to facilitate the observance of the recommended maximum intervals between meals and snacks. ${ }^{29,30}$ ONS were recommended according to the temporal availability to assure patient preference and the lowest possible adherence barriers. We suggested liquid polymeric $(1,5 \mathrm{kcal} / \mathrm{mL})$ or oligomeric $(1 \mathrm{kcal} / \mathrm{mL})$ preparations with total daily volumes of $400 \mathrm{~mL}$, and $600 \mathrm{~mL}$ respectively, intending to cover $600 \mathrm{kcal}$ of energy intake between meals. ${ }^{27,31} \mathrm{We}$ 
identified 222 patients receiving polymeric and 228 patients having oligomeric formulas respectively. Furthermore, the team provided a graphic template for keeping a daily record of the amount of ingested ONS (Figure 1A, courtesy Pavel Kohout, Charles University, Prague, Czech Republic). Although electronic prescription was not available and ONS dispensing required an in-person specialist visit within 30 and 90 days, ONS were fully reimbursed by insurance. In addition to the dietary advice and ONS, patients have been encouraged to exercise 15-20 minutes daily for 2 to 3 times a week (Figure 1B). ${ }^{31}$

For this study, adherence has been defined as a categorical variable at the time of pre-scheduled followup visits at 30, 90, and 180 days. Non-adherence was also observed in some cases during the index hospitalization. After discharge, observance of adherence was supported by three sources, each of which has been previously validated: 1) a recorded interview of study nurse with the patient during pre-scheduled visits (with the conclusion adherent/ non-adherent), 2) pre-printed daily record of used ONS filled and dated by the patient with evidence of at least $80 \%$ of the prescribed volume ingested, and 3) pharmacy signed refill records confirming at least $80 \%$ of ONS dispensed. Patients were considered as non-adherent in the absence of evidence for adherence or if they were not seen in the clinic at prescheduled visits, or when lost to follow-up.

During follow-up, all patients had pre-scheduled visits within 30, 90, and 180 days. Patients who showed-up at follow-up visits had an anthropometric, laboratory, nutritional, and functional parameters reevaluated. The follow-up was stopped on the date of liver transplantation and/or death whichever occurred first or was censored at least one year after inclusion.

For the analysis of adherence, patients who did not survive until the date of pre-scheduled visit $(30,90,180$ days) were not included ( $\mathrm{n}=61,106,140)$ at the time-point and later (Figure 2). Likewise, patients undergoing LT before the time-point while adhering to ONS until the LT $(n=21)$ were not included. The follow-up was terminated at the time of the LT (as alive) or death (as dead), whichever occurred first. In the remaining cases, it was censored at least one year after inclusion into the study. Mortality was verified in all patients from the national registry of deceased inhabitants, also including patients who were lost to follow-up.

All procedures involving human participants have been approved according to the ethical standards of the institutional research committee, including the 1964 Helsinki
A

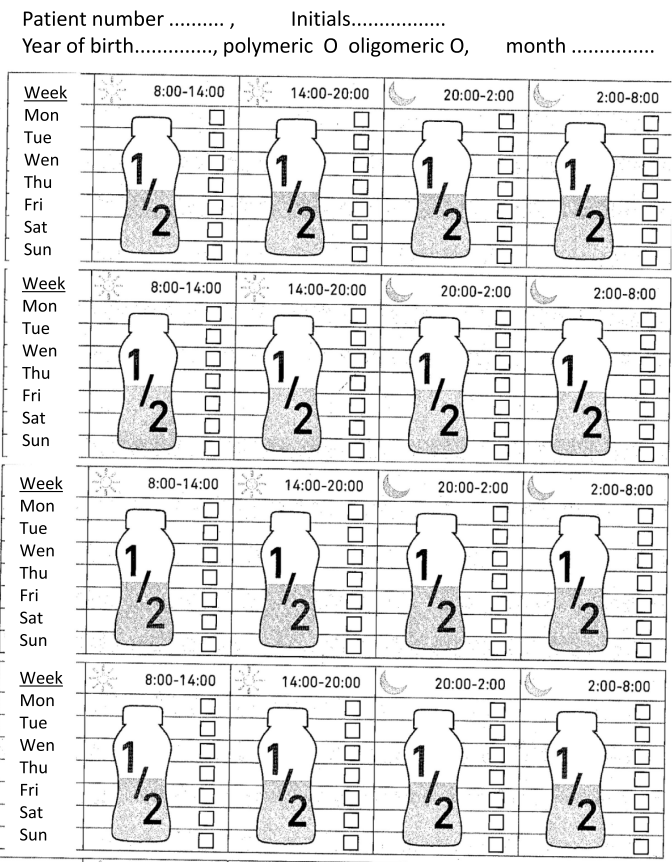

B

The exercises below are given as a suggestion, which can be performed during the day for 15-20 minutes, ideally 2-3 times a week.

Excersise intructions:

- Make sure to have fresh air in the room

- Excersice more than one hour after a meal

- Stop excercising when you feel pain

- Keep yourself safe during excercise, beware of slippery floor

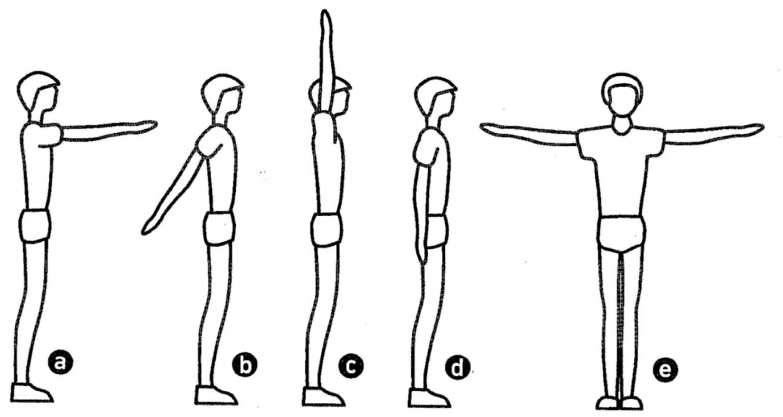

Courtesy, Pavel Kohout, Charles University, Prague, Czech Republic

Figure I The exact instructions which were given to ACLD patients being discharged from the hospital (A) recommendation on the use of oral nutritional supplements with the record of ingested volume during four 6-hour time-periods, (B) instructions on the frequency, duration, and character of recommended exercises. 


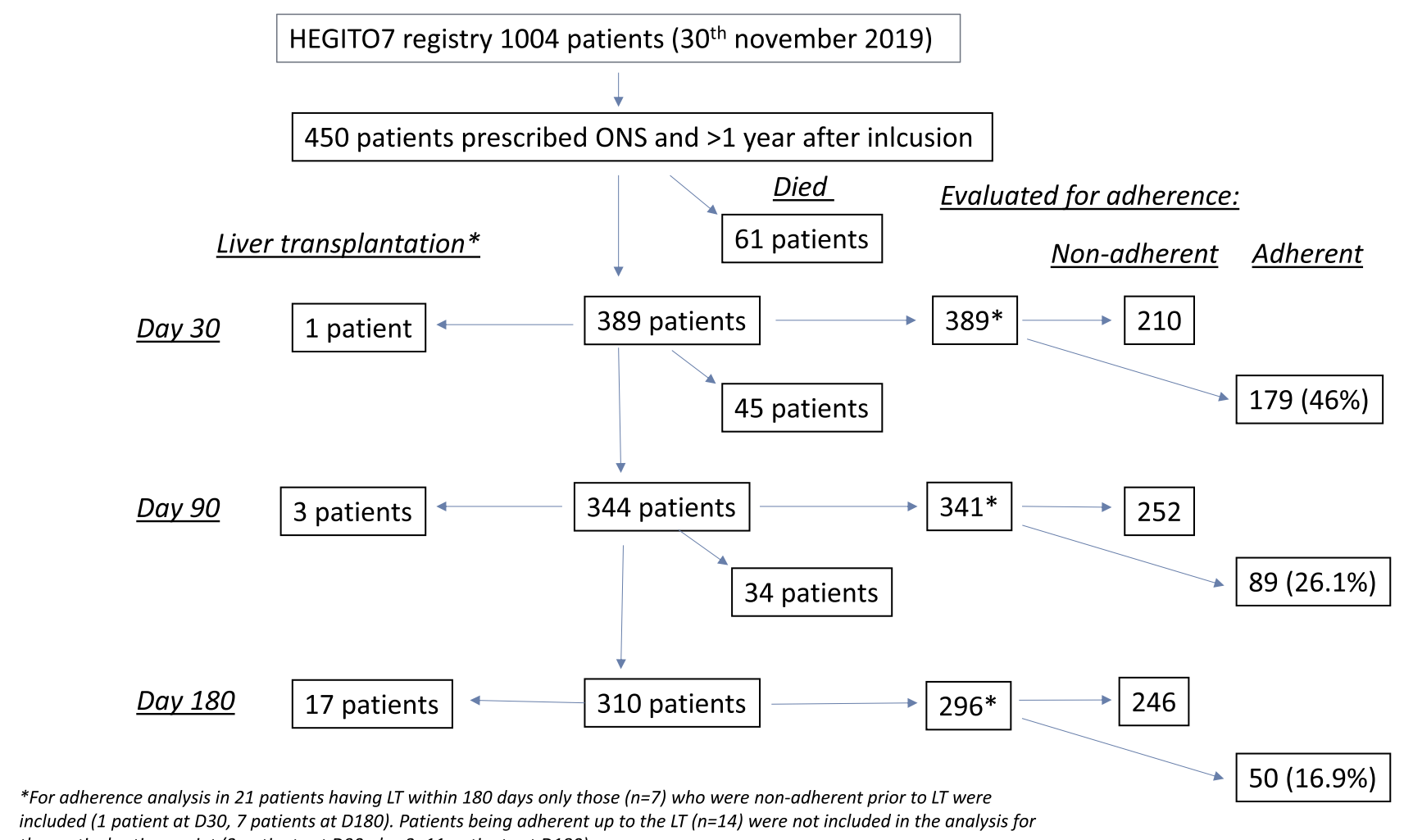

the particular time-point ( 3 patients at D90 plus $3+11$ patients at D180).

Figure 2 Flow-chart of 450 included ACLD patients after being discharged from the hospital illustrating the adherence to oral nutritional supplements and outcome during the first 180 days of follow-up.

Declaration and its later amendments (www.wma.net) or comparable ethical standards. The reported clinical and research activities are consistent with the Principles of the Declaration of Istanbul, as outlined in the Declaration of Istanbul on Organ Trafficking and Transplant Tourism. ${ }^{32}$ All patients signed informed consent before enrolment in the study and data acquisition to HEGITO7 registry of which we are unique creators was approved by the local ethics committee, name of the ethics committee: Etická komisia Fakultnej Nemocnice s Poliklinikou F. D. Roosevelta (in English: Ethics committee of the Faculty Hospital F.D. Roosevelt), address: Etická komisia, FNsP FD Roosevelta, Nám. L. Svobodu 1, 97517 Banská Bystrica, Slovakia, date of approval: May 21st, 2014.

\section{Statistical Analysis}

Due to the non-normal distribution of data, numerical parameters are presented as median and 25-75 percentiles with proportions given as numbers and percentages. To identify baseline factors associated with adherence for more than 30 days, we used logistic regression with adherence as a dependent variable and all relevant baseline covariates as independent variables. Hazard ratios are provided for each covariate separately in a univariate model. Besides, the stepwise conditional backward regression yielded independently associated factors according to their P-value in a multivariable model (Table 3). To illustrate the impact of adherence ( $>30$ days) on survival, we plotted the cumulative incidence of death or LT (Figure 3) and applied the Gray test for competing events yielding hazard ratios for LT or death occurring within 1 year. The model has been further stratified according to MELD score $(>16$ vs $\leq 16)$, CTP stage $C$, low HGS $(<30 \mathrm{~kg}$ in men, $<20 \mathrm{~kg}$ in women), and the presence of refractory ascites (Figure 4.). For comparison of numerical parameters and proportions during followup, we used a paired Wilcoxon test and McNemar test respectively. Missing values were treated as missing and were not accounted for in statistical models. Statistical analysis has been carried out using the $\mathrm{R}$ software ( $\mathrm{R}$ foundation for statistical computing, www.r-project.org), $\mathrm{R}$ Studio (v.1.2.5033, RStudio Inc. for macOS) with the EZR plugin ${ }^{33}$ and MedCalc (MedCalc Software Ltd, Ostend, Belgium). 

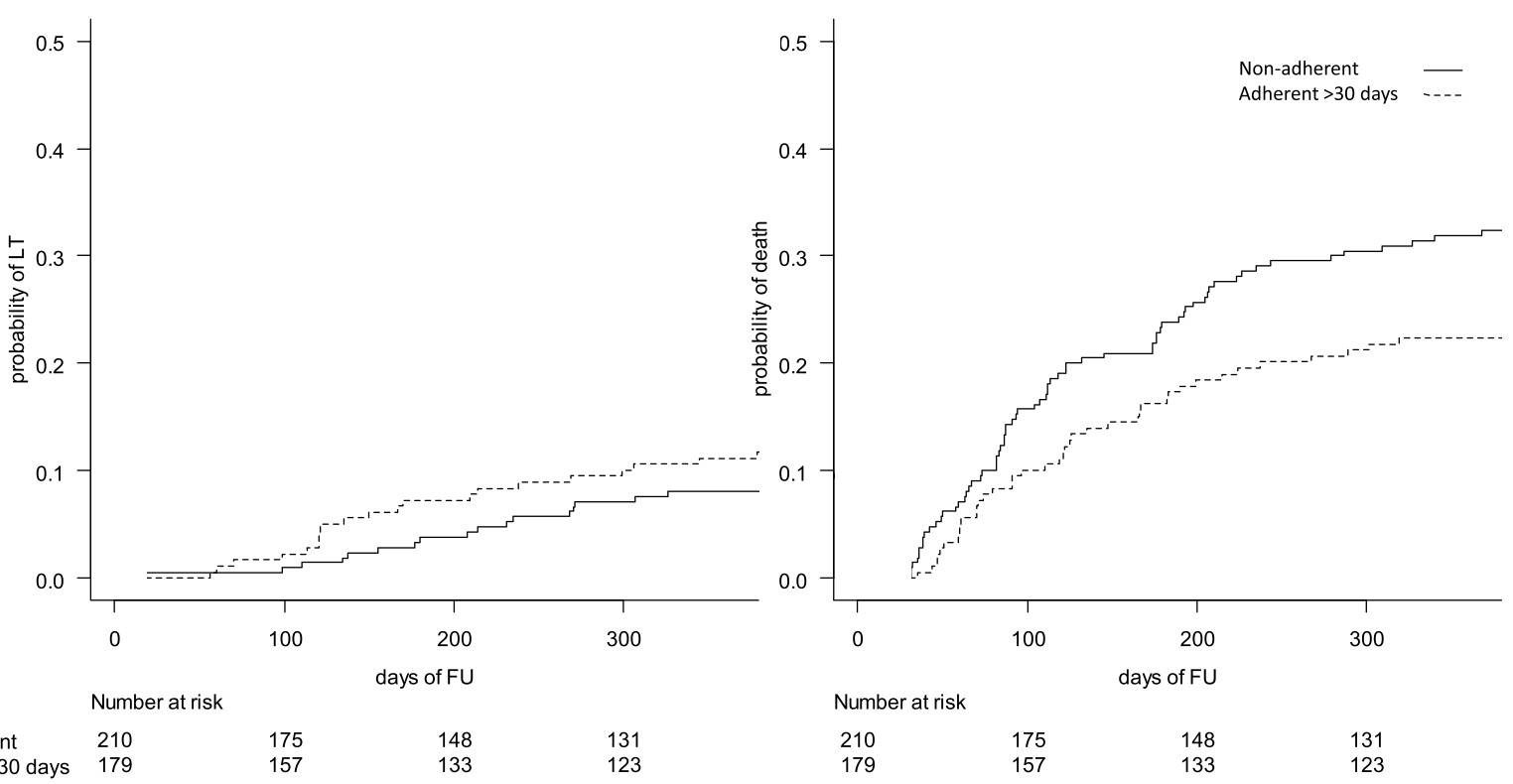

Figure 3 The cumulative incidence of liver transplantation (left pane) and death (right pane) in discharged ACLD patients according to adherence to oral nutritional supplements ( $>30$ days, yes or no).

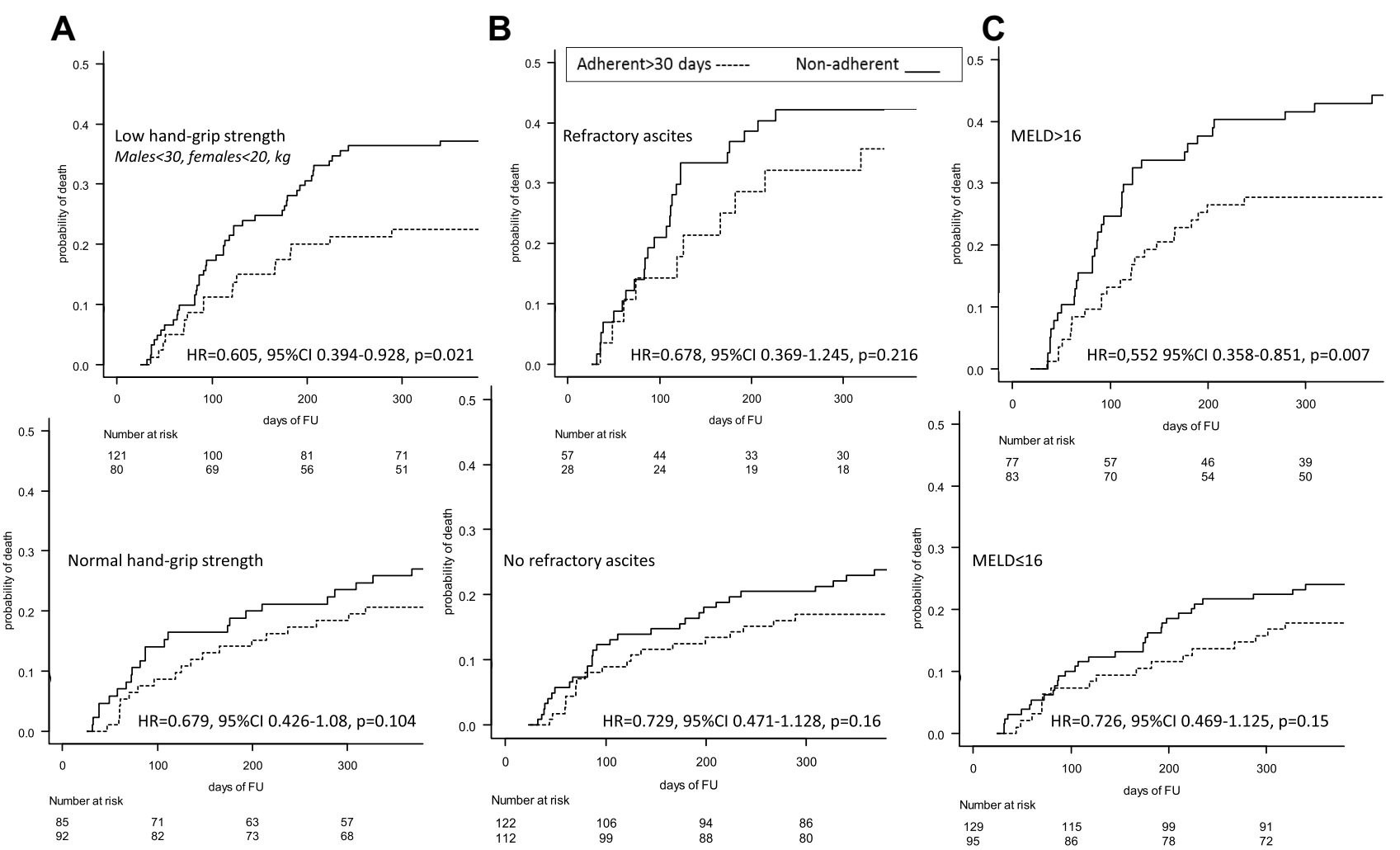

Figure 4 The cumulative incidence of death in discharged ACLD patients according to adherence to oral nutritional supplements ( $>30$ days, dotted line) or not (solid line), a comparison of subgroups: (A) low or normal hand grip strength, (B) refractory ascites, yes or no, (C) MELD score $>16$ or $\leq 16$. 


\section{Results}

From the HEGITO7 registry containing 1004 patients, we identified 450 cases with documented ONS prescriptions after discharge. The median age was 56.3 years (25-75 percentile $46.6-62.3), 60 \%$ were males, with the median MELD of 16 (11-21), $63.8 \%$ having alcoholic etiology. The summary statistics are displayed in Table 1.

During the first 6 months of follow-up, 21 patients underwent the LT and 140 patients died. Three-hundred and eighty-nine patients survived for at least 30 days including 179 (46\%) who adhered to ONS and 210 (54\%) who did not, 344 patients survived for 90 days including 89 (26.1\%) who adhered to ONS and 252 who did not, 310 patients survived for 180 days including 50 (16.9\%) who adhered to ONS and 246 who did not. We observed no difference in adherence between the group receiving polymeric and oligomeric formulas. The complete flowchart of all included patients is displayed in Figure 2.

Analysis of the factors associated with non-adherence is displayed in Table 2. Of 210 patients who survived but did not adhere for 30 days, $136(64.7 \%)$ did not show up at the pre-scheduled visit not allowing us to record the reason for stopping ONS. From the remaining 74 patients, more frequent causes of stopping were abdominal fullness (7.1\%), non-compliance due to palatability $(6.2 \%)$, diarrhea $(4.8 \%)$, and failure to control glycemia (3.3\%). Univariate regression for baseline factors associated with adherence for 30 days is displayed in Table 3. In the multivariable regression model, three baseline factors were independently associated with adherence: refractory ascites (OR 0.429 95\% CI 0.244-0.756), hand-grip strength (OR 1.03, 95\% CI 1.01-1.06), and mid-arm circumference (0.929 95\% CI 0.876-0.984).

Finally, we assessed the impact of adherence on the outcome, survival, and the chance of LT.

Comparison of the baseline with available data on days 30,90 , and 180 according to adherence is displayed in Table 4. In patients who were adherent for at least 30 days we observed a consistent and significant improvement in the MELD score, muscle strength, mid-arm circumference, serum albumin, C-reactive protein, and number connection test, but the proportion of patients with refractory ascites did not change. Among 389 patients who survived for more than 30 days, the followup likelihood of LT was significantly higher (Figure 3, left pane, HR $1.795 \%$ CI 1.03-2.8, p=0.039) and the incidence of death was significantly lower (Figure 3, right pane, HR $0.6595 \%$ CI $0.45-0.89, \mathrm{p}=0.007$ ) among adherent compared to non-adherent patients. The incidence curve for mortality has been further stratified according to the MELD score, CTP stage C, low HGS, and RA. Adherence significantly decreased the risk of death among patients with MELD $>16(\mathrm{HR}=0.552$, 0.$358-0.851, \mathrm{p}=0.007)$, but not in patients with MELD $\leq 16$ $(\mathrm{HR}=0.726,0.469-1.125, \mathrm{p}=0.15)$. Adherence decreased the risk of death among patients with CTP stage $\mathrm{C}(\mathrm{HR}=0.657,0.428-1.008, \mathrm{p}=0.055)$ with borderline significance, but not in patients with CTP stages $A$ and B $(H R=0.701,0.452-1.086, p=0.11)$. Adherence significantly decreased the risk of death among patients with low HGS (HR $=0.605,0.394-0.928, p=0.021)$, but not in patients with normal HGS (HR $=0.679,0.426-1.08$, $\mathrm{p}=0.104)$. Adherence did not significantly decrease the risk of death in patients with RA (HR=0.678, 0.369-$1.245, \mathrm{p}=0.216)$, or without $\mathrm{RA}(\mathrm{HR}=0.729,0.471-1.128$, $\mathrm{p}=0.16$ ).

\section{Discussion}

In the present study, we report evidence of a steep decline in the adherence to ONS after discharge in patients with ACLD. Within 30, 90, and 180 days, only 46\%, 26.1\%, and $16.9 \%$ of patients adhered. We identified independently associated baseline factors: refractory ascites and higher mid-arm circumference decreasing adherence and higher muscle strength increasing adherence. In adherent patients, we also observed an improvement in the parameters of muscle mass and strength, synthetic liver function, and the MELD score. Among patients who survived beyond 30 days, those who adhered for more than 30 days had a higher likelihood of undergoing LT and a significantly lower risk of death during further followup.

World Health Organization has underscored adherence as the priority in the prevention of harm and ineffective health-care expenditure. ${ }^{34}$ Adherence to the prescribed medication in chronic conditions varies significantly and it is presumably affected by a mix of factors from the patient, the disease, the physician, and the health-care system. ${ }^{14-16}$ Several categories of non-adherence have been proposed: intentional, unintentional, financial, and sociological. The potential harm of non-adherence has been classified as high-risk, medium, or low-risk but the majority of medications taken by cirrhotic patients are non-ACLD therapies. ${ }^{36}$ 
Table I Summary Statistics and Study Group Characteristics of 450 Hospitalized ACLD Patients

\begin{tabular}{|c|c|c|}
\hline Factor & Group & N (\%), Median [25-75\%] \\
\hline $\mathrm{n}$ & & 450 \\
\hline Age, y & & $56.33[46.63,62.28]$ \\
\hline \multirow[t]{2}{*}{ Sex $(\%)$} & Males & $252(60)$ \\
\hline & Females & $198(44.0)$ \\
\hline \multirow[t]{2}{*}{ Disease etiology (alcohol/viral/NAFLD/autoimmune/other) } & $\mathrm{n}$ & $287 / 32 / 66 / 50 / 15$ \\
\hline & $\%$ & $63.8 / 7.1 / 14.7 / 11.1 / 3.3$ \\
\hline Diabetes type 2 (\%) & & $65(14.4)$ \\
\hline Body mass index $(\mathrm{kg} / \mathrm{m} 2)$ & & $26.26[23.05,29.81]$ \\
\hline Mid-arm circumference, $\mathrm{cm}$ & & $26.00[23.62,30.00]$ \\
\hline Tricipital skinfold, mm & & $12.10[7.80,19.00]$ \\
\hline Handgrip strength (HGS), kg & & $23.50[16.78,32.35]$ \\
\hline Low HGS (men<30, women<20, kg) & & $246(54.6)$ \\
\hline White blood cells, count*10*9/I & & $5.70[3.90,8.67]$ \\
\hline C-reactive protein, mg/l & & $12.03[5.11,26.93]$ \\
\hline Refractory ascites (\%) & & $106(23.5)$ \\
\hline MELD-Na score & & $16.00[11.00,21.00]$ \\
\hline MELD-Na score $>16$ & & $209(46.4)$ \\
\hline Child-Pugh-Turcotte score & & $9.00[8.00,11.00]$ \\
\hline Child-Pugh-Turcotte stage $C(>9)$ & & $220(48.9)$ \\
\hline Serum bilirubin, umol/l & & $54.80[24.00,124.67]$ \\
\hline Serum albumin, g/l & & $26.00[23.00,31.00]$ \\
\hline Number connection test, $s$ & & $103.00[74.25,136.00]$ \\
\hline Mortality 30 days (\%) & & $61(13.6)$ \\
\hline Mortality 90 days (\%) & & $106(23.6)$ \\
\hline Mortality 180 days (\%) & & $140(3 \mid .1)$ \\
\hline \multirow[t]{3}{*}{ Follow-up event (\%) } & None & $156(34.7)$ \\
\hline & LT & $62(13.8)$ \\
\hline & Death & $232(51.6)$ \\
\hline \multirow[t]{4}{*}{ Days of follow-up by event } & All & $452.00[91.50,1268.25]$ \\
\hline & None & $1347[1225,1576]$ \\
\hline & LT & $270[15 I, 470]$ \\
\hline & Death & III.5 $[27.75,4 \mid 4.25]$ \\
\hline
\end{tabular}

Abbreviations: ACLD, advanced chronic liver disease; HGS, hand-grip strength; NAFLD, nonalcoholic fatty liver disease; MELD, model for end-stage liver disease; LT, liver transplantation. 
Table 2 Reported Causes of Non-Adherence During the First 30 Days of Treatment with ONS

\begin{tabular}{|l|l|l|}
\hline Nutritional Supplements & $\mathbf{n}$ & $\%$ \\
\hline Unknown & 136 & 64.7 \\
Abdominal fullness & 15 & 7.1 \\
Non-compliance & 13 & 6.2 \\
Diarrhea & 10 & 4.8 \\
Intolerance, other & 8 & 3.8 \\
Diabetes/glycaemia control & 7 & 3.3 \\
Nausea & 6 & 2.9 \\
Abdominal pain & 5 & 2.4 \\
Weigh gain & 4 & 1.9 \\
Anorexia & 3 & 1.4 \\
Constipation & $\mathrm{I}$ & 0.5 \\
Heartburn & $\mathrm{I}$ & 0.5 \\
Skin eruptions & $\mathrm{I}$ & 0.5 \\
Total & 210 & 100 \\
\hline
\end{tabular}

Abbreviation: ONS, oral nutritional supplements.

\section{Adherence in ACLD}

Adherence rates to standard ACLD medications have been previously reported by several authors. Hayward et al have pointed out frequent discrepancies among self-reported medication lists and medical records which occurred in $54 \%$ of patients. ${ }^{37}$ Another study has reported adherence to more than $75 \%$ of prescribed doses of oral lactulose in only $30 \%$ of patients. ${ }^{38}$ Serper et al have reported that $86 \%$ of patients with cirrhosis displayed correct medication knowledge, 78\% could demonstrate their drug regimen while $14 \%$ of patients self-reported as non-adherent. ${ }^{39}$ A recent study among 181 liver transplantation candidates identified $70 \%$ of patients as low-adherers according to the Morisky Medication Adherence Scale (MMAS-8). Low adherence was associated with a higher number of medications, medication complexity, diabetes, and lower self-perceived health. In a multivariate analysis, only medication number was significantly associated with low adherence. ${ }^{40}$ A recent study by Hayward et al among patients with decompensated cirrhosis has reported non-adherence in $31.5 \%$ and it was judged as intentional in $65.3 \%$ of patients. ${ }^{36}$ Moreover, the prevalence of non-adherence with high-risk of potential harm (diuretics, propranolol, SBP prophylaxis) was $20 \%$ and has been associated with disease severity (MELD, CTP score, Charlson Comorbidity Index). Factors explaining the reason for nonadherence have been explored by several of the mentioned studies identifying two domains, complexity of medication expressed as medication complexity index, and psychological factors such as medication concern relative to necessity

Table 3 Factors Associated with Adherence $>30$ Days in Univariate and Multivariate Analysis

\begin{tabular}{|c|c|c|c|c|c|c|c|}
\hline & \multicolumn{4}{|c|}{ Univariate } & \multicolumn{3}{|c|}{ Multivariate* } \\
\hline & OR & & $95 \% \mathrm{Cl}$ & $P$ value & OR & $95 \% \mathrm{Cl}$ & $P$ value \\
\hline Age, y & 0.976 & $*$ & $0.959-0.994$ & 0.01 & & & \\
\hline Sex (\%), male & 0.99 & $*$ & $0.6626-1.48$ & 0.241 & & & \\
\hline Alcoholic etiology (\%) & 1.07 & $*$ & $0.71-1.61$ & 0.22 & & & \\
\hline Diabetes type 2 (\%) & 0.665 & $*$ & $0.371-1.19$ & 0.352 & & & \\
\hline \multicolumn{8}{|l|}{ Baseline parameters } \\
\hline Body mass index (kg/m2) & 0.983 & $*$ & $0.955-1.011$ & 0.438 & & & \\
\hline Mid-arm circumference, $\mathrm{cm}$ & 0.985 & $*$ & $0.945-1.027$ & 0.474 & 0.929 & $0.876-0.984$ & 0.013 \\
\hline Tricipital skinfold, mm & 0.987 & $*$ & $0.962-1.013$ & 0.327 & & & \\
\hline Hand-grip strength, $\mathrm{kg}$ & 1.016 & $*$ & $0.997-1.035$ & 0.095 & 1.03 & $1.01-1.06$ & 0.015 \\
\hline Leucocytes, $\times 10 * 9 / 1$ & 1.029 & $*$ & $0.982-1.079$ & 0.223 & & & \\
\hline C-reactive protein, $\mathrm{mg} / \mathrm{l}$ & 0.999 & $*$ & $0.989-1.008$ & 0.803 & & & \\
\hline Refractory ascites (\%) & 0.535 & $*$ & $0.318-0.900$ & 0.018 & 0.429 & $0.244-0.756$ & 0.003 \\
\hline MELD-Na score & 1.005 & $*$ & $0.976-1.034$ & 0.76 & & & \\
\hline Serum bilirubin, umol/l & 1.002 & $*$ & $1.000-1.004$ & 0.02 & & & \\
\hline Serum albumin, $g / l$ & 1.025 & $*$ & $0.993-1.059$ & 0.13 & & & \\
\hline Number connection test, $s$ & 0.996 & $*$ & $0.9916-1.000$ & 0.099 & & & \\
\hline \multicolumn{8}{|l|}{ Outcome } \\
\hline Mortality at 90 days & 0.549 & & $0,285-1,06$ & 0.073 & & & \\
\hline Mortality at 180 days & 0.619 & & $0,372-1,03$ & 0.064 & & & \\
\hline
\end{tabular}

Notes: *Variables in the multivariate logistic regression model; Overall model fit, chi-squared I5.5; $\mathrm{P}=0.0014 ; \mathrm{Nagelkerke} \mathrm{R}^{2}=0.064 ; \mathrm{AUROC}=0.62 \pm 0,03 ; 95 \% \mathrm{Cl}$ $0,564-0,674$. 


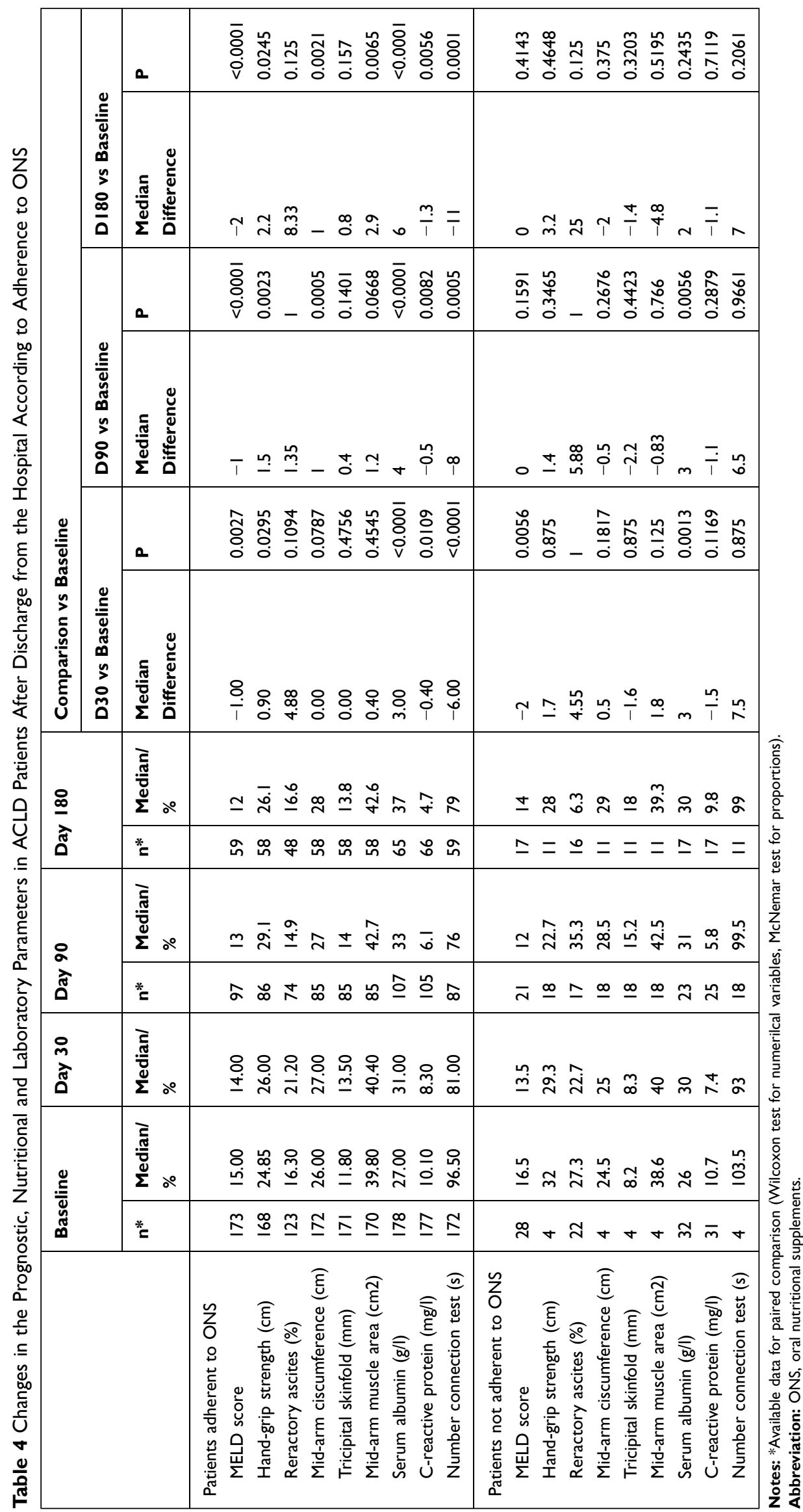


beliefs ${ }^{41}$, perception of treatment helpfulness, forgetfulness, as well as symptom burden, and low quality of life. ${ }^{31,32}$

\section{Adherence to ONS}

Very few studies have assessed adherence to ONS after discharge in free-living patients. In non-ACLD patients, a study in 96 cases with malignant or digestive diseases reported $93 \%$ adherence underscoring the importance of ONS tailoring by a dietician. ${ }^{42}$ Also, a recent systematic review has reported good adherence. ${ }^{43}$ In contrast, achieving adequate protein and calorie intake in ACLD is more difficult and requires a refined approach. ${ }^{8,9,36}$ Our study brings more evidence that adherence to ONS is low, even when compared with rates for standard ACLD medications. We observed two types of non-adherence during the initial follow-up for 30 days. First, 35\% of cases stopped ONS for various side effects (Table 2) resembling the rate of adherence to a low-sodium diet, ${ }^{44}$ lactulose $(29,31)$, or ONS in alcoholic liver disease. ${ }^{11,45}$ Apart from a side effect profile of ONS, it could be driven by low palatability and high complexity. In this regard, it is of interest that we did not find any means of calculating the medication complexity index for ONS. However, considering variables that are usually included, ONS use requires regular and precise intake schedules resembling a more complex medication regimen. Second, $65 \%$ of patients did not show up for further visits. From the multivariate model, disease severity (refractory ascites) was the major driving force of non-adherence together with low muscle strength and higher MAC. Unlike studies observing adherence to standard ACLD medications, we did not find any association with MELD or the CTP scores. Nevertheless, our findings could be considered consistent. Patients with refractory ascites have more severe disease and often complain of delayed gastric emptying, early satiety, and high symptom burden. The association of non-adherence with lower muscle strength may reflect the degree of frailty and sarcopenia. These conditions are also associated with disease severity and undoubtedly bring more logistical and administrative barriers to visiting a care-provider or getting an ONS refill. The association with MAC is more intriguing, but a perception of treatment helpfulness in patients with low MAC could be higher in comparison to patients with high MAC. We also believe that other factors could have been involved. For example, a lower recognition of nurse-led care as compared to physician-led care, the patient-perceived lower authority of nurse in our social and health care setting, or inability to achieve an educational goal during a single 30-minute counseling. Unfortunately, our registry did not contain data allowing us to explore more reasons for non-adherence.

\section{Adherence and Outcome}

Non-adherence has general implications on the adverse outcome of chronic diseases increasing the rate of rehospitalizations, ${ }^{35,46}$ economic burden, ${ }^{47}$ morbidity, and mortality. ${ }^{48}$ In non-ACLD patients, the effect of ONS on the outcome of malnourished patients has been previously reported. Among older adults, adherence to ONS covering more $>500 \mathrm{kcal} /$ day decreased the rate of rehospitalization and the overall health care cost 3-5 times. ${ }^{49}$ In another study among 308 primary care malnourished patients, ONS for 12 weeks and dietary advice were superior to dietary advice alone in decreasing health care use (visits, emergency admissions, and length of stay) and improving the quality of life. ${ }^{50}$ Moreover, 3-months therapy with ONS in 80 malnourished patients with benign digestive diseases has improved muscle function and the quality of life. $^{51}$

In ACLD patients, Iwasa et al have reported that nutritional counseling compared with no counseling improved the long-term survival of ACLD patients. Besides, in counseled cases who participated in regular courses with a multidisciplinary education team, survival has further improved. ${ }^{52}$ Overall, a meta-analysis of the available evidence in 2013 had been slightly in favor of nutritional supplementation in ACLD but admitted that adequately powered and stratified studies were lacking at the time. ${ }^{25}$ The more recent meta-analysis has confirmed the beneficial effect of shortening the post-absorptive phase in the form of a late evening snack by improving nutritional status and liver function. ${ }^{14}$ Thus, our study brings more evidence, that nutritional counseling together with adherence to ONS significantly improves prognostic parameters (MELD, albumin, NCT), muscle function (HGS), survival, and the chance for LT.

In our study, we also observed a greater benefit of ONS in patients with higher MELD and lower HGS. Although the previous study reported a beneficial effect only in patients with CTP class $\mathrm{A},{ }^{52}$ there is some evidence that in severe patients effective short-term nutritional intervention prevents further progression of the disease. ${ }^{10}$ However, the benefit of this approach has been questioned by the conclusion of a subsequent controlled trial in alcoholic liver disease with jaundice. ${ }^{11}$ In this study, adherence was also a significant issue since, in the treatment arm, 15 
out of 46 patients discontinued enteral nutrition and additional 2 patients were lost to follow-up. The same pattern has been reported by authors of the study among 136 patients with severe alcoholic hepatitis. ${ }^{45}$ The intention to treat analysis did not show any benefit in survival in patients receiving corticoids with enteral nutrition compared to corticoids with standard nutrition for 6 months. Authors however did notice lower mortality among patients who received higher caloric intake $(\geq 21.5 \mathrm{kcal} /$ $\mathrm{kg} /$ day) compared to those who did not. This evidence brings forward the major problem of the studies assessing the benefit of nutritional therapy on the outcome of ACLD. Patients' clinical status with multiple disease complications often results in low adherence not allowing the intention to treat analysis to capture the true benefit of the assigned treatment. Our study thus brings more evidence for the argument, that when patients with severe disease can tolerate nutritional support in sufficient amounts, they do have benefit. It is also consistent with a recently introduced concept of the natural history of ALCD which points-out that malnutrition and frailty are driving forces of disease worsening leaving patients more susceptible to infection and/or ACLF. ${ }^{53}$

Our findings expose the existence of a vicious circle, whereby liver disease severity is associated with worse adherence while sicker patients appear to have more benefit from ONS. Among ACLD patients, there appear to be three groups of patients in terms of the priority of nutritional intervention. First, mortality within 30 days in hospitalized patients is driven mainly by disease complications. Inhospital management should focus on identifying and addressing them. Urgent treatment strategies need to be prioritized since patients with uncertain prognosis such as those with severe systemic infection and/or multiple organ failure, or acute-on-chronic liver failure (ACLF) are usually unable to tolerate any nutritional support. ${ }^{54}$ Second, there are patients with a severe disease such as refractory ascites and/ or chronic decompensation, who can tolerate some nutritional support. In this group, the early introduction of nutritional support in the form of enteral nutrition or ONS should be attempted. Third, in clinically stabilized patients before discharge, clinicians should allow for sufficient education of the patient and caregiver. Depending on their learning capacity, adequate time should be dedicated to meeting educational goals while identifying barriers to adherence, ${ }^{13}$ and managing side effects. Although the efficacy of this nutritional tailoring approach has been previously reported in the non-ACLD population, it is yet to be tested in the setting of
ACLD. ${ }^{38}$ Considering the current evidence, non-adherence to ONS in discharged patients should be considered high-risk for potential harm. Our study also supports evidence from the previous report that adherence to a physician visit within 30days after discharge remains among the management objectives when caring for patients with ACLD. ${ }^{55,56}$ Hence, we propose that both aspects of adherence be included among the quality of care measures for ACLD patients.

\section{Limitations of the Study}

Our study has several limitations. First, data from the registry did not allow the analysis of barriers to adherence concerning psychological, financial, and social factors. Second, we assessed adherence as a categorical variable at three time-points assigning patients not attending the pre-scheduled visits as non-adherent. The strict definition of adherence was more robust, but it could have missed the care given to patients outside of our hospital with the reported rate underestimating the true adherence. Also, our data did not allow for assessing the exact amount of ingested calories. Third, in designing the registry we did not incorporate a quantitative adherence scale such as the MMAS-8 and we did not evaluate adherence to other ACLD medications which would allow the assessment of adherence with medication number and complexity. Fourth, there is an inherent causal relationship between survival and adherence since surviving patients had a chance for longer adherence. To overcome this limitation, in the analysis of adherence at 30 days we excluded all patients who could not reach 30 days of follow-up, namely those who died or underwent LT. In contrast, patients with documented non-adherence during hospitalization or before LT were included. This approach also excluded the sickest patients in whom due to their poor general condition nutritional supplements could not be tolerated and its benefit on survival would not be expected. Thus, adherent and non-adherent patients for 30 days were evaluated for survival or the chance of LT occurring after 30 days. Fifth, outcome parameters were assessed only in patients coming in to have a pre-scheduled visit. These patients were mostly adherent to ONS with a decreasing number of observations over time. Also, the group of nonadherent patients was too low for allowing sufficient statistical power to compare the groups and the difference in the outcome parameters should be interpreted with caution. A low number of patients with refractory ascites did not allow sufficient statistical power to address the impact of adherence on survival in this subgroup of patients. 
However, a relatively large cohort of patients did allow the stratified assessment of adherence and survival according to MELD, CTP score, or HGS.

\section{Conclusion}

Among patients with advanced chronic liver disease after being discharged from the hospital, adherence to oral nutritional supplements was low and sharply declined over time. It has worsened in the presence of refractory ascites and improved with muscle strength. In adherent patients, prognostic parameters and muscle mass and strength had improved. In patients who survived 30 days and were adherent beyond 30 days, we observed a higher likelihood of undergoing LT and lower mortality, with greater benefit in patients with high MELD and low muscle strength.

\section{Disclosure}

Lubomir Skladany reports personal fees and non-financial support from Nestle, during the conduct of the study; and non-financial support from Nutricia, personal fees from Nestle. All other authors report no potential conflicts of interest in this work.

\section{References}

1. Národné centrum zdravotníckych infromácií. Zdravotnícka Ročenka Slovenskej Republiky 2018; 2019.

2. Carvalho L, Parise ER. Evaluation of nutritional status of nonhospitalized patients with liver cirrhosis. Arq Gastroenterol. 2006;43 (4):269-274. doi:10.1590/s0004-28032006000400005

3. Kuftinec G, Ram Bhamidimarri K, Pearlman M. Malnutrition in cirrhosis: frequent but overlooked. Liver Transplant off Publ Am Assoc Study Liver Dis Int Liver Transplant Soc. 2019;25(12):1743-1744. doi:10.1002/lt.25660

4. Ferreira LG, Ferreira Martins AI, Cunha CE, Anastácio LR, Lima AS, Correia MITD. Negative energy balance secondary to inadequate dietary intake of patients on the waiting list for liver transplantation. Nutrition. 2013;29(10):1252-1258. doi:10.1016/j.nut.2013.04.008

5. Cardenas A. Commentary: oral or enteral nutritional supplementation in cirrhosis. Aliment Pharmacol Ther. 2013;37(10):1022-1023. doi:10.1111/apt.12302

6. Montano-Loza AJ, Meza-Junco J, Prado CMM, et al. Muscle wasting is associated with mortality in patients with cirrhosis. Clin Gastroenterol Hepatol. 2012;10(2):166-173, 173.e1. doi:10.1016/j. cgh.2011.08.028

7. Stickel F, Inderbitzin D, Candinas D. Role of nutrition in liver transplantation for end-stage chronic liver disease. Nutr Rev. 2008;66 (1):47-54. doi:10.1111/j.1753-4887.2007.00005.x

8. Plauth M, Bernal W, Dasarathy S, et al. ESPEN guideline on clinical nutrition in liver disease. Clin Nutr. 2019;38(2):485-521. doi:10.1016/ j.clnu.2018.12.022

9. European Association for the Study of the Liver. EASL clinical practice guidelines on nutrition in chronic liver disease. J Hepatol. 2019;70 (1):172-193. doi:10.1016/j.jhep.2018.06.024
10. Cabre E, Gonzalez-Huix F, Abad-Lacruz A, et al. Effect of total enteral nutrition on the short-term outcome of severely malnourished cirrhotics: a randomized controlled trial. Gastroenterology. 1990;98 (3):715-720. doi:10.1016/0016-5085(90)90293-a

11. Dupont B, Dao T, Joubert C, et al. Randomised clinical trial: enteral nutrition does not improve the long-term outcome of alcoholic cirrhotic patients with jaundice. Aliment Pharmacol Ther. 2012;35 (10):1166-1174. doi:10.1111/j.1365-2036.2012.05075.x

12. Mizubuti YGG, Vieira ELM, Silva TA, et al. Comparing the effects of whey and casein supplementation on nutritional status and immune parameters in patients with chronic liver disease: a randomized double-blind controlled trial. Br J Nutr. 2020:1-12. doi:10.1017/ S0007114520003219

13. Ginzburg Y, Shmilovitz I, Monastyrsky N, Endevelt R, Shahar DR. Barriers for nutritional care in the transition from hospital to the community among older patients. Clin Nutr ESPEN. 2018;25:56-62. doi:10.1016/j.clnesp.2018.04.004

14. Chen C-J, Wang L-C, Kuo H-T, Fang Y-C, Lee H-F. Significant effects of late evening snack on liver functions in patients with liver cirrhosis: a meta-analysis of randomized controlled trials. $J$ Gastroenterol Hepatol. 2019;34(7):1143-1152. doi:10.1111/jgh.14665

15. Tandon P, Raman M, Mourtzakis M, Merli M. A practical approach to nutritional screening and assessment in cirrhosis. Hepatology. 2017;65(3):1044-1057. doi:10.1002/hep.29003

16. Tandon P, Tangri N, Thomas L, et al. A rapid bedside screen to predict unplanned hospitalization and death in outpatients with cirrhosis: a prospective evaluation of the clinical frailty scale. $\mathrm{Am}$ J Gastroenterol. 2016;111(12):1759-1767. doi:10.1038/ajg.2016.303

17. Liljeberg E, Andersson A, Lövestam E, Nydahl M. Incomplete descriptions of oral nutritional supplement interventions in reports of randomized controlled trials. Clin Nutr. 2018;37(1):61-71. doi:10.1016/j.clnu.2017.03.024

18. De Geest S, Sabaté E. Adherence to long-term therapies: evidence for action. Eur J Cardiovasc Nurs J Work Gr Cardiovasc Nurs Eur Soc Cardiol. 2003;2(4):323. doi:10.1016/S1474-5151(03)00091-4

19. Burnier M. Is there a threshold for medication adherence? Lessons learnt from electronic monitoring of drug adherence. Front Pharmacol. 2018;9(1540):1-8. doi:10.3389/fphar.2018.01540

20. Brown MT, Bussell JK. Medication adherence: WHO cares? Mayo Clin Proc. 2011;86(4):304-314. doi:10.4065/mcp.2010.0575

21. Fischer MA, Stedman MR, Lii J, et al. rimary medication non-adherence: analysis of 195,930 electronic prescriptions. J Gen Intern Med. 2010;25(4):284-290. doi:10.1007/s11606-010-1253-9

22. Jüngst $C$, Gräber $S$, Simons $S$, Wedemeyer $H$, Lammert $F$. Medication adherence among patients with chronic diseases: a survey-based study in pharmacies. QJM. 2019;112(7):505-512. doi:10.1093/qjmed/hcz058

23. Polis S, Zang L, Mainali B, et al. Factors associated with medication adherence in patients living with cirrhosis. J Clin Nurs. 2016;25(1-2):204-212. doi:10.1111/jocn.13083

24. Marina Heeb R, Greif Higer G, Lutz J, et al. A comparative, multicenter, observational study of medication adherence in liver cirrhosis patients and dialysis patients using electronic event measurement. $J$ Pharm Care Heal Syst. 2017;04(04):186. doi:10.4172/2376-0419.1000186

25. Ney M, Vandermeer B, van Zanten SJ, Ma MM, Gramlich L, Tandon P. Meta-analysis: oral or enteral nutritional supplementation in cirrhosis. Aliment Pharmacol Ther. 2013;37(7):672-679. doi:10.1111/apt.12252

26. Skladany L, Koller T, Molcan P, et al. Prognostic usefulness of serum myostatin in advanced chronic liver disease: its relation to gender and correlation with inflammatory status. $J$ Physiol Pharmacol. 2019;70:3. doi:10.26402/jpp.2019.3.03

27. EASL Clinical Practice. Guidelines on nutrition in chronic liver disease. J Hepatol. 2019;70(1):172-193. doi:10.1016/j.jhep.2018. 06.024 
28. Lai JC, Tandon P. How I approach it: improving nutritional status in patients with cirrhosis. Am $J$ Gastroenterol. 2018;113 (11):1574-1576. doi:10.1038/s41395-018-0080-1

29. Hirsch S, Bunout D, de la Maza P, et al. Controlled trial on nutrition supplementation in outpatients with symptomatic alcoholic cirrhosis. JPEN J Parenter Enteral Nutr. 1993;17(2):119-124. doi:10.1177/ 0148607193017002119

30. Saunders J, Brian A, Wright M, Stroud M. Malnutrition and nutrition support in patients with liver disease. Frontline Gastroenterol. 2010;1 (2):105-111. doi:10.1136/fg.2009.000414

31. Tandon P, Ismond KP, Riess K, et al. Exercise in cirrhosis: translating evidence and experience to practice. $J$ Hepatol. 2018;69 (5):1164-1177. doi:10.1016/j.jhep.2018.06.017

32. Muller E, Dominguez-Gil B, Martin D. The declaration of istanbul on organ trafficking and transplant tourism (2018 Edition). Transplantation. 2019;103(2):218-219. doi:10.1097/TP.0000000000002540

33. Kanda Y. Investigation of the freely available easy-to-use software 'EZR' for medical statistics. Bone Marrow Transplant. 2012;48:452. doi:10.1038/bmt.2012.244

34. World Health Organization. Adherence to Long-Term Therapies: Evidence for Action; 2003.

35. Gajdosik J. Adherence to treatment - an important part of reaching therapeutic effects on chronic conditions. AtheroRev. 2017;2 (1):15-19.

36. Hayward KL, Patel PJ, Valery PC, et al. Medication-related problems in outpatients with decompensated cirrhosis: opportunities for harm prevention. Hepatol Commun. 2019;3(5):620-631. doi:10.1002/ hep4.1334

37. Hayward KL, Valery PC, Cottrell WN, et al. Prevalence of medication discrepancies in patients with cirrhosis: a pilot study. $B M C$ Gastroenterol. 2016;16(1):114. doi:10.1186/s12876-016-0530-4

38. Thomson MJ, Lok AS, Tapper EB. Optimizing medication management for patients with cirrhosis: evidence-based strategies and their outcomes. Liver Int off J Int Assoc Study Liver. 2018;38 (11):1882-1890. doi:10.1111/liv.13892

39. Serper M, Patzer RE, Reese PP, et al. Medication misuse, nonadherence, and clinical outcomes among liver transplant recipients. Liver Transpl. 2015;21(1):22-28. doi:10.1002/lt.24023

40. Kuo SZ, Haftek M, Lai JC. Factors associated with medication non-adherence in patients with end-stage liver disease. Dig Dis Sci. 2017;62(2):543-549. doi:10.1007/s10620-016-4391-z

41. Hayward KL, Valery PC, Martin JH, et al. Medication beliefs predict medication adherence in ambulatory patients with decompensated cirrhosis. World J Gastroenterol. 2017;23(40):7321-7331. doi:10. 3748/wjg.v23.i40.7321

42. Liljeberg E, Andersson A, Blom Malmberg K, Nydahl M. High adherence to oral nutrition supplements prescribed by dietitians: a cross-sectional study on hospital outpatients. Nutr Clin Pract off Publ Am Soc Parenter Enter Nutr. 2019;34(6):887-898. doi:10.1002/ ncp. 10243

43. Hubbard GP, Elia M, Holdoway A, Stratton RJ. A systematic review of compliance to oral nutritional supplements. Clin Nutr. 2012;31 (3):293-312. doi:10.1016/j.clnu.2011.11.020

44. Morando F, Rosi S, Gola E, et al. Adherence to a moderate sodium restriction diet in outpatients with cirrhosis and ascites: a real-life cross-sectional study. Liver Int off J Int Assoc Study Liver. 2015;35 (5):1508-1515. doi:10.1111/liv.12583
45. Moreno C, Deltenre P, Senterre C, et al. Intensive enteral nutrition is ineffective for patients with severe alcoholic hepatitis treated with corticosteroids. Gastroenterology. 2016;150(4):903-910.e8. doi:10.1053/ j.gastro.2015.12.038

46. Stratton RJ, Hébuterne X, Elia M. A systematic review and meta-analysis of the impact of oral nutritional supplements on hospital readmissions. Ageing Res Rev. 2013;12(4):884-897. doi:10.1016/ j.arr.2013.07.002

47. Cutler RL, Fernandez-Llimos F, Frommer M, Benrimoj C, GarciaCardenas V. Economic impact of medication non-adherence by disease groups: a systematic review. BMJ Open. 2018;8(1):e016982. doi:10.1136/bmjopen-2017-016982

48. Rodriguez F, Maron DJ, Knowles JW, Virani SS, Lin S, Heidenreich PA. Association of statin adherence with mortality in patients with atherosclerotic cardiovascular disease. JAMA Cardiol. 2019;4(3):206-213. doi:10.1001/jamacardio.2018.4936

49. Seguy D, Hubert H, Robert J, Meunier JP, Guérin O, RaynaudSimon A. Compliance to oral nutritional supplementation decreases the risk of hospitalisation in malnourished older adults without extra health care cost: prospective observational cohort study. Clin Nutr. 2019. doi:10.1016/j.clnu.2019.08.005

50. Smith TR, Cawood AL, Walters ER, Guildford N, Stratton RJ. Ready-made oral nutritional supplements improve nutritional outcomes and reduce health care use-a randomised trial in older malnourished people in primary care. Nutrients. 2020;12(2):517. doi:10.3390/nu12020517

51. Norman K, Kirchner H, Freudenreich M, Ockenga J, Lochs H, Pirlich M. Three month intervention with protein and energy rich supplements improve muscle function and quality of life in malnourished patients with non-neoplastic gastrointestinal disease-a randomized controlled trial. Clin Nutr. 2008;27(1):48-56. doi:10.1016/j. clnu.2007.08.011

52. Iwasa $\mathrm{M}$, Iwata $\mathrm{K}$, Hara $\mathrm{N}$, et al. Nutrition therapy using a multidisciplinary team improves survival rates in patients with liver cirrhosis. Nutrition. 2013;29(11-12):1418-1421. doi:10.1016/j. nut.2013.05.016

53. Lai JC, Dodge JL, Sen S, Covinsky K, Feng S. Functional decline in patients with cirrhosis awaiting liver transplantation: results from the functional assessment in liver transplantation (FrAILT) study. Hepatology. 2016;63(2):574-580. doi:10.1002/hep.28316

54. Praktiknjo M, Clees C, Pigliacelli A, et al. Sarcopenia is associated with development of acute-on-chronic liver failure in decompensated liver cirrhosis receiving transjugular intrahepatic portosystemic shunt. Clin Transl Gastroenterol. 2019;10(4):e00025. doi:10.14309/ ctg.0000000000000025

55. Serper M, Kaplan DE, Shults J, et al. Quality measures, all-cause mortality, and health care use in a national cohort of veterans with cirrhosis. Hepatology. 2019;70(6):2062-2074. doi:10.1002/hep. 30779

56. Kanwal F, Tapper EB, Ho C, et al. Development of quality measures in cirrhosis by the practice metrics committee of the American Association for the study of liver diseases. Hepatology. 2019;69 (4):1787-1797. doi:10.1002/hep.30489 


\section{Publish your work in this journal}

Patient Preference and Adherence is an international, peer-reviewed, open access journal that focusing on the growing importance of patient preference and adherence throughout the therapeutic continuum. Patient satisfaction, acceptability, quality of life, compliance, persistence and their role in developing new therapeutic modalities and compounds to optimize clinical outcomes for existing disease states are major areas of interest for the journal. This journal has been accepted for indexing on PubMed Central. The manuscript management system is completely online and includes a very quick and fair peer-review system, which is all easy to use. Visit http:// www.dovepress.com/testimonials.php to read real quotes from published authors. 